\title{
BIM no curriculo de Arquitetura: Visões e reflexões para uma implementação
}

\author{
> Vivian Delatorre \\ UFSC / UNOCHAPECÓ, Brasil \\ viviandelatorre.arq@gmail.com
}

\author{
> Alice Theresinha Cybis Pereira \\ UFSC, Brasil \\ acybis@gmail.com
}

\begin{abstract}
The BIM is being gradually incorporated in education. Based on national and international reports, experiences have shown that it is not only the insertion of a technology applied to project development and construction, but it also covers significant changes involving people and processes that require collaborative, interdisciplinary and integrated practices. In this context, a study for the implementation of BIM, considering the particularities of the Architecture and Urbanism course at Unochapecó University was developed, once the curriculum is written based on these discussions. The teachers involved were interviewed for get different views on the subject and to seek contributions.
\end{abstract}

Keywords: BIM (Building Information Modeling); Education; Architecture.

\section{Introdução}

Aos poucos o BIM (Building Information Modeling) vem sendo implementado no ensino. Relatos de experiências nacionais e internacionais têm mostrado que não se trata apenas de introduzir uma tecnologia aplicada ao desenvolvimento do projeto e construção, mas abranger mudanças significativas envolvendo pessoas e processos que requerem práticas colaborativas, interdisciplinares e integradas (Kiviniemi, 2013; Ruschel; Andrade; Morais, 2013; Taylor; Hein, 2008; Eastman et al., 2014).

Ruschel et al. (2011), aborda que: "um dos primeiros passos para a consolidação do BIM no ensino é a rediscussão dos currículos dos cursos de arquitetura e engenharia civil".

Neste contexto, um estudo para a implementação do BIM, considerando as particularidades do curso de Arquitetura e Urbanismo da Universidade Comunitária da Região de Chapecó (UNOCHAPECÓ) é iniciado, uma vez que a matriz atual se constrói a partir de discussóes sobre tecnologias, entre elas o BIM. Sendo que algumas iniciativas de inserção do BIM em disciplinas curriculares, estavam sendo implementadas na matriz anterior.

Os professores envolvidos na construção da matriz atual foram entrevistados, com o propósito de conhecer as diferentes visóes a respeito da implementação do BIM e buscar contribuições para o pré-lançamento da proposta de implementação. A proposta está em fase de desenvolvimento e será embasada com o enfoque na integração no currículo com base na abordagem de Taylor; Hein, 2008.

Espera-se com este trabalho, poder avançar para a implementaçáo do BIM no ensino de Arquitetura do curso mencionado.
Assim como gerar reflexóes em outros cursos a fim de despertar iniciativas para revisão de seus currículos frente às mudanças que ocorrem com BIM.

\section{Metodologia}

Com o objetivo de conhecer a visão dos docentes envolvidos no desenvolvimento da matriz 1003, sobre a implementação do BIM no ensino, aplicou-se a técnica de entrevista semiestruturada. A escolha da técnica se deu, pela flexibilidade de discorrer sobre o tema através de um roteiro tendo a liberdade para novos questionamentos.

O roteiro das entrevistas foi baseado em questôes afirmativas, onde os entrevistados expressaram o grau de concordância e discordância das afirmaçóes por meio de escala Lykert de cinco pontos. Após cada questâo foi aberto para comentários e novos questionamentos, que foram gravados para posterior transcrição.

As entrevistas semiestruturadas foram realizadas de forma presencial, com os professores que compóem o Núcleo Docente Estruturante (NDE), do curso de Arquitetura e Urbanismo da UNOCHAPECÓ, e também por aqueles que contribuíram para a construçáo da matriz atual (1003). Os dados serão apresentados em forma de gráfico, com breve interpretação.

\section{Breve interpretação das entrevistas}

Para análise dos dados da entrevista gerou-se um gráfico (figura 01), seguido de uma breve interpretação das respostas e discussôes geradas com os docentes, de cada afirmativa que compôs o roteiro de entrevista. Segue as interpretaçóes das entrevistas: 


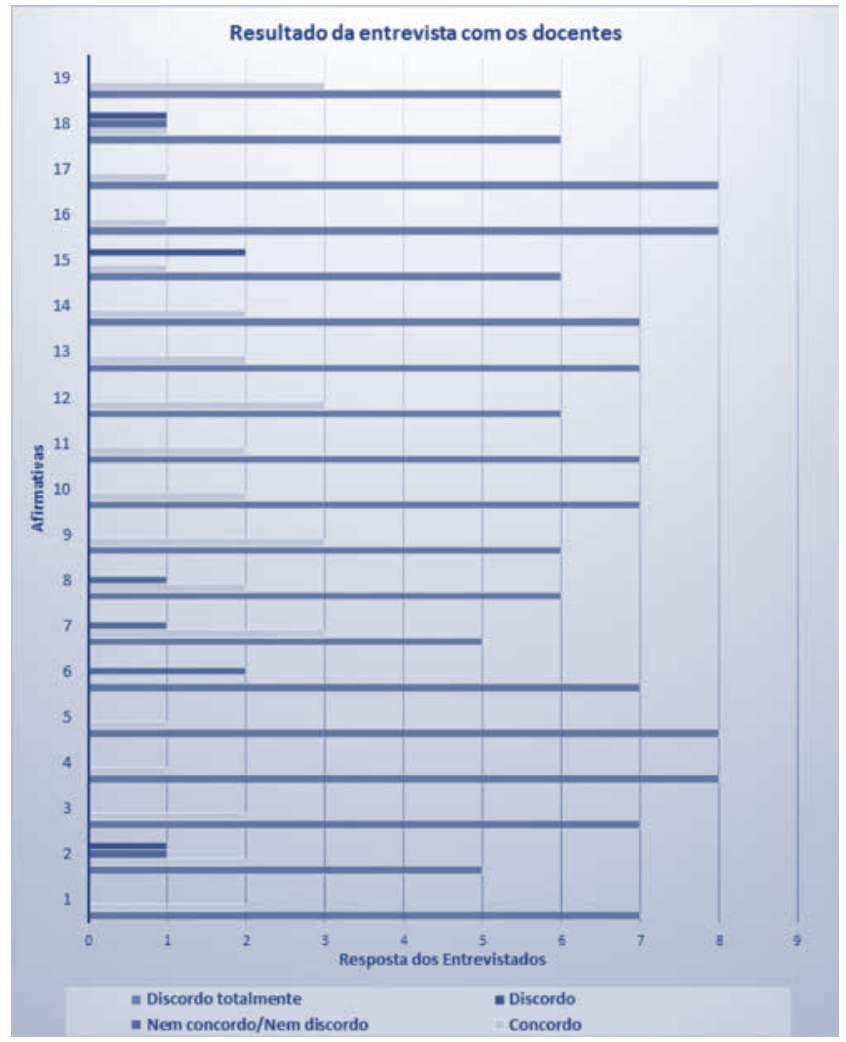

Figura Øl: Gráfico com o resultado da entrevista com os docentes (Delatorre, 2014).

Sobre a implementação (afirmativa 01), os professores percebem a importância da implementação do BIM no currículo de Arquitetura e Urbanismo.

Quanto a introduzir o BIM na primeira fase, em disciplina de desenho arquitetônico (afirmativa 02), alguns (poucos) professores ainda têm dúvida se a substituição do desenho à mão (técnico) pela ferramenta BIM, tem ou não perdas no processo de ensino aprendizagem.

$\mathrm{Na}$ questão relacionada a implementação do BIM, houve consenso dos docentes, em começar nas disciplinas de projeto arquitetônico (afirmativa 03).

Quanto a importância de estimular as práticas colaborativas e interdisciplinares e a inserçấo gradativa do BIM (afirmativa 04), o resultado mostra o interesse por parte dos professores.

Em relação a reconhecer o papel docente, para estimular atividades colaborativas e integradas (afirmativa 05), verifica-se que os professores reconhecem a importância de articular estas práticas.

Quando abordado sobre uma das formas de estimular a integração e colaboração seria: trabalhar de maneira individual apenas nas primeiras fases e as demais fases em grupo (afirmativa 06), os entrevistados que responderam de forma neutra, pensam que os conceitos de integração e colaboração são importantes, mas ressaltam que não necessariamente devem ocorrem em uma fase específica.

Quanto ao CAD não ser pré-requisito do BIM (afirmativa 07), os professores, em sua maioria, percebem que os alunos que iniciam em software BIM têm menor resistência quanto ao uso da ferramenta e sua inserção no processo.
Sobre os professores utilizarem ferramentas BIM em sala de aula (afirmativa 08), os docentes se mostraram dispostos a ensinar alguns recursos de ferramentas BIM, associados aos conteúdos de suas disciplinas, a fim de potencializar o ensino aprendizagem. Alguns ressaltaram a falta de tempo em função do cronograma e a aprendizagem dos professores para com as ferramentas BIM.

Em relação ao uso do BIM em disciplina de desenho arquitetônico potencializar o processo de ensino aprendizagem e auxiliar na compreensão do aluno em desenhos bidimensionais e tridimensionais (afirmativa 09). A maior parte concordou com a afirmativa, mas houve ressalvas sobre a importância de existir alguns momentos de desenho à mão, não necessariamente por instrumento.

Quanto à importância da projetação tridimensional apoiada pelo BIM (afirmativa 10), reconhecem principalmente pela flexibilidade do nível de detalhamento em cada fase.

Sobre o BIM auxiliar nas diferentes etapas do processo de projeto (afirmativa 11), os entrevistados não têm restrição quanto ao uso do BIM em nenhuma fase de desenvolvimento do projeto arquitetônico. No entanto, salientam a importância da expressão das ideias através do croqui e também da materialização, integradas ao processo BIM.

Quanto ao potencial do BIM como ferramenta de projeto (afirmativa 12), grande parte dos professores entende a diferença do BIM como ferramenta de projeto e náo apenas de desenho e também os conceitos de colaboração e integração. No entanto, alguns (poucos) náo incorporaram muito bem os conceitos, ou seja, ainda o entendem apenas como ferramenta de desenho.

Sobre o uso do BIM para análises e simulaçóes e integração das disciplinas de Projeto e Conforto (afirmativa 13), os professores apoiam a integração entre as disciplinas. Principalmente como incentivo à tomada de decisão do aluno ainda nas fases de concepção, relacionadas ao desempenho do edifício. Alguns professores levantam dúvidas sobre o potencial dos softwares de conforto, se integrados ao BIM, quanto à aplicação sem gerar retrabalhos.

Quanto a importância desenvolver habilidades relacionadas ao trabalho colaborativo e integrado aliado ao BIM, através de cursos, workshops e/ou disciplinas (afirmativa 14), os professores concordam.

Em relação ao êxito da integração das disciplinas da $7^{a}$ fase, com ênfase na coordenação em BIM, estar relacionada a integração dos professores e planejamento das etapas (afirmativa 15). Os professores concordam que isto é necessário para que a experiência obtenha uma resposta positiva. Os que discordam acham complicado por considerar essencial ao aluno, o conhecimento prévio, para posterior aplicação. Alguns sugerem a possibilidade de maior foco às compatibilizaçóes e aplicaçóes/conceitos BIM e menor ênfase às questôes conceituais e plásticas do projeto arquitetônico.

Sobre a possível criação de disciplinas que aprofunde o conhecimento do aluno em BIM, buscando a integração com outros cursos (afirmativa 16), a resposta foi bem positiva. Mas ressaltaram a importância de iniciativas que despertem o interesse dos demais cursos, por exemplo, as engenharias.

Quanto a importância de não restringir o aluno a uma única ferramenta BIM (afirmativa 17), os docentes indicam a necessidade de ofertar cursos, na universidade, abrangendo outras ferramentas. 
Como também, promover testes de interoperabilidade, demostrando os desafios do mercado.

Em relação a sugestão de aprofundar o conhecimento em modelagem de objetos paramétricos, em disciplinas curriculares e ou cursos, no intuito de contribuir para a criação de bibliotecas para o mercado/indústria (afirmativa 18). Alguns consideram que a iniciativa contribui para a aprendizagem do aluno quanto às questóes de detalhamentos e modulação. $\mathrm{O}$ entrevistado cuja resposta foi nula, apenas não concorda em ser em disciplinas curriculares. Já o entrevistado que discorda pensa que por se tratar de objetos, mobiliários e elementos náo se deve estimular o aluno da arquitetura, por entender como um campo da profissão do design.

Quanto a importância da implementação do BIM no curso e os desafios (afirmativa 19). Os entrevistados aceitam a implementação do BIM na matriz curricular do curso de Arquitetura e Urbanismo. Em sua maioria, acreditam que o maior desafio é o professor, por considerarem que este é fundamental neste processo e pensam que nem todos estão dispostos.

$\mathrm{O}$ resultado das entrevistas mostra que a maior parte dos professores se enxerga no processo. Alguns comentaram sobre a necessidade de atualização, principalmente relacionadas aos softwares BIM. A opiniāo é diversificada quanto ao grau de importância desse domínio por parte dos professores.

Alguns docentes acreditam não ser necessário um domínio maior sobre as ferramentas. Estes entendem que os professores que não se adaptarem podem ter apoio de monitores e que o mais importante é estimular os alunos quanto ao processo. Outros acham que o professor deve ter um domínio das ferramentas.

\section{Estudo para a Implementação}

A matriz curricular (matriz 1003) do curso de Arquitetura e Urbanismo da UNOCHAPECÓ é composta por 10 semestres (figura 02) e está estruturada da seguinte forma: a) Estruturação profissional, composta pelas linhas de arquitetura e urbanismo, b) Fundamentação, que abrange as disciplinas propedêuticas, da pesquisa e expressão gráfica, c) Articulação Profissional, que envolve disciplinas de história teoria e crítica, construção e conforto. Além de disciplinas eletivas, a disciplina de tópicos integradores tem a função de oferecer flexibilidade de conteúdo conforme a necessidade e a demanda dos acadêmicos.

A matriz curricular do curso de Arquitetura e Urbanismo (matriz 1003) foi amplamente discutida, com o corpo docente, em 2013. A maioria apoia o uso das tecnologias e os novos processos - a matriz 1003 se constrói a partir das discussóes.

Devido à restriçáo de quantidade de horas para grande quantidade de conteúdos indispensáveis a formação do aluno, não se pode incluir muitas disciplinas que aprofundem conteúdos relacionados às tecnologias, entre elas o BIM. Mas entende-se que é possível incluir parte destes conteúdos em disciplinas curriculares.

Considerando o BIM não apenas como tecnologia, mas um processo que envolve mudanças culturais principalmente em relação às pessoas por meio das práticas colaborativas e interdisciplinares, acredita ser importante a sua introduçáo nos currículos de Arquitetura e Urbanismo.

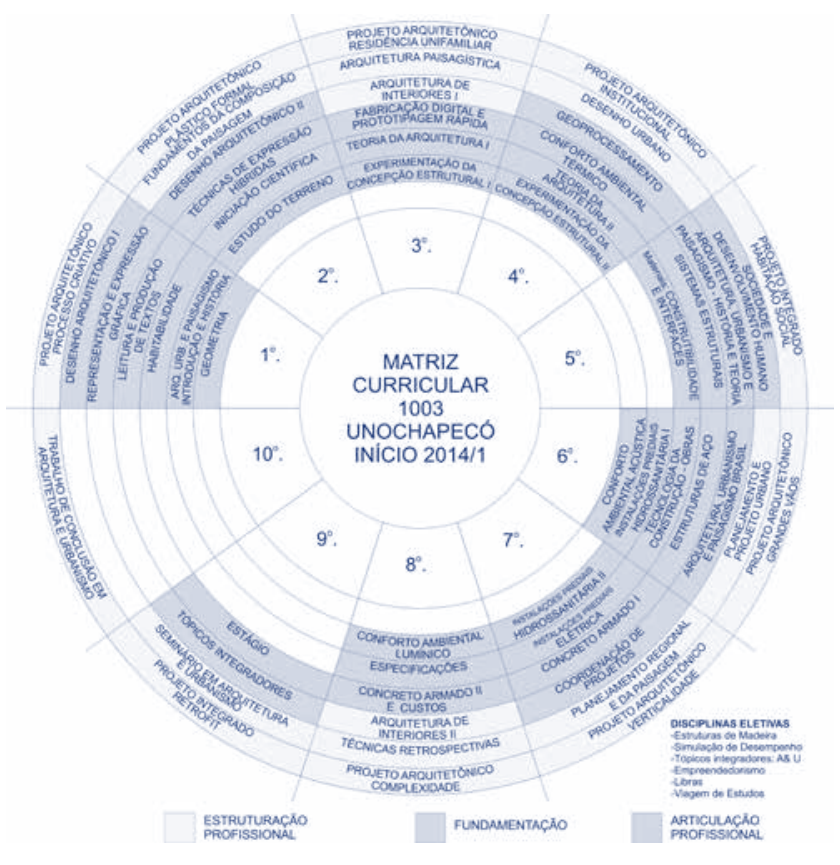

Figura 02: Matriz curricular do Curso de Arquitetura e Urbanismo da UNOCHAPECÓ, (Delatorre, 2014).

Busca-se tirar partido das potencialidades do BIM para contribuir na formação do aluno frente aos desafios do mercado que aos poucos vem adotando o BIM como aliado no setor da AEC (Arquitetura, Engenharia e Construção).

Tendo em vista a complexidade do BIM, mas a importância de iniciativas que promovam a sua inserção no ensino. É iniciado um pré-lançamento da proposta de implementação do BIM no currículo de Arquitetura e Urbanismo da UNOCHAPECÓ. Primeiramente com foco voltado as disciplinas de projeto arquitetônico, buscando compreender o nível de competência em BIM que é requerida ao aluno em cada projeto arquitetônico e identificando a interdisciplinaridade.

São considerados os níveis de competência (figura 03) identificados por Barison e Santos (2011), sem incorporar os estágios (introdutório, intermediário e avançado), por supor que existe uma transição entre estes estágios, que podem variar, por exemplo, o nível de detalhamento da modelagem ou nível de análise/simulação.

Além disso, os estágios (figura 03) definidos por Succar (2008), auxiliaram no entendimento das fases de implementação do BIM, a fim de identificar em qual estágio é possível inserir o BIM no curso em questão considerando o seu contexto. 


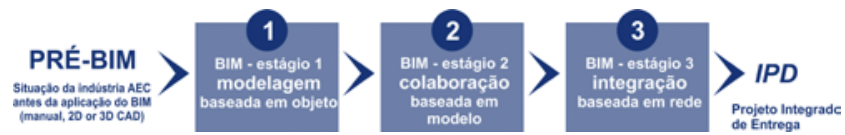

Figura 04: Estágios identificados por Succar (2008).

As habilidades envolvendo pessoas, processos e tecnologias (figura 05) apresentadas por Kiviniemi (2013), ajudam a estabelecer uma relação das habilidades. Assim como as competências definidas por Barison e Santos (2011), em cada disciplina de projeto arquitetônico, considera-se a ementa de cada disciplina de projeto com as disciplinas identificadas passíveis de integração.

As ementas das disciplinas de projeto arquitetônico de cada semestre da matriz curricular 1003 do Curso de Arquitetura e Urbanismo da UNOCHAPECÓ são analisadas, identificando os temas e os conteúdos, além das disciplinas que podem trabalhar em conjunto visando a um processo interdisciplinar.

Entende-se que todas as disciplinas podem dar apoio à disciplina de projeto arquitetônico e trabalhar de forma interdisciplinar, por exemplo, as disciplinas teóricas. Mas como foco está nas disciplinas de projeto arquitetônico, busca-se identificar disciplinas que tenham alguma atividade de ordem projetiva e de representaçáo gráfica, relacionadas a linha para trabalhar a interdisciplinaridade.

Após a leitura e entendimento das ementas, identificaram-se as disciplinas que podem trabalhar de forma interdisciplinar, por terem relação com a temática e conteúdo de cada projeto. E identificadas as competências em BIM, segundo definição de Barison; Santos (2011), conforme a figura 06, visando a estruturaçáo da proposta futura.

Entende-se que, pelas definiçóes de Barison; Santos (2011), para que os alunos tenham competências de Gerente BIM é necessária a integração entre cursos. Assim as competências são apresentadas como modelador e analista, embora a $7^{\mathrm{a}}$ e a $9^{\mathrm{a}}$ fases requeiram habilidades de coordenador de projetos as quais vão além da competência de analista.

Acredita-se que, para incluir a competência de Gerente BIM, é necessário implementar o BIM não apenas no curso de arquitetura, mas também nos cursos de engenharia. Busca-se a integração

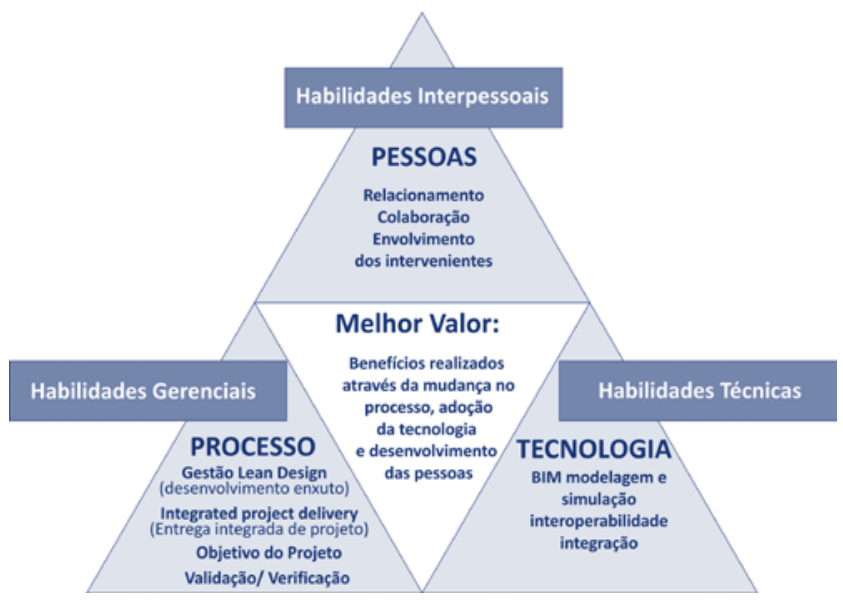

Figura 05: Habilidades em BIM apresentadas por Kiviniemi (2013).

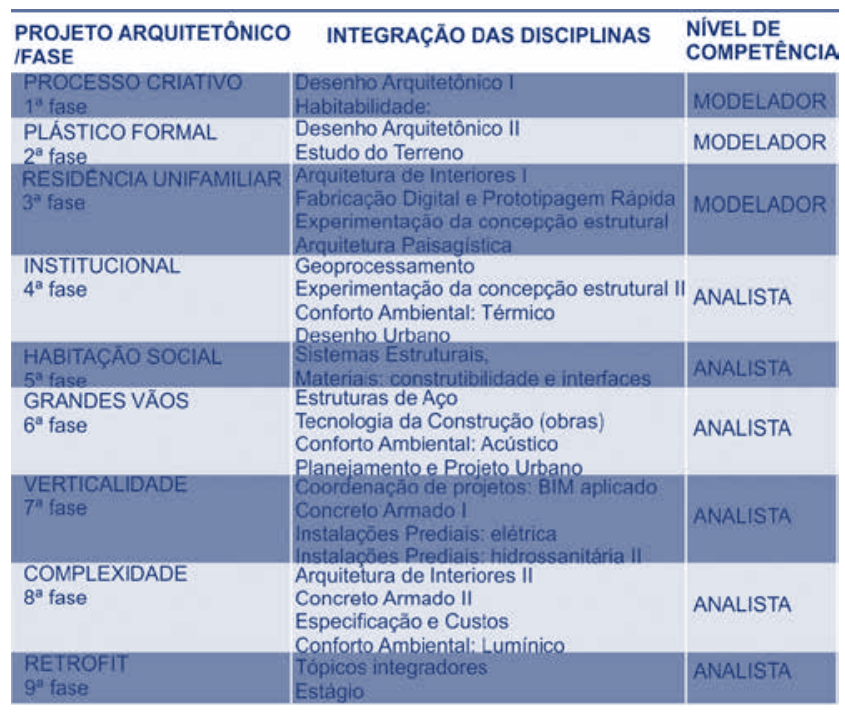

Figura Ø6: Identificação dos níveis de competência em BIM, com base na definição de Barison; Santos (2011).

deles e estimulam-se os alunos para uma experimentação em nível mais avançado.

O pré-lançamento da proposta teve por objetivo organizar informaçóes e ideias, as quais as entrevistas com os professores trouxeram grandes contribuiçôes. Apresenta-se um esquema gráfico (figura 07) que demostra a organização das ideias para a proposta, que está em fase de desenvolvimento.

A proposta final contará com uma estrutura mais detalhada, apresentando a inserção do BIM de forma gradativa e apontando a integração das disciplinas de cada semestre, com as disciplinas de Projeto Arquitetônico, através dos conteúdos com foco nas habilidades/competências em BIM que podem ser desenvolvidas com os alunos. Assim como serão indicadas estratégias extracurriculares que complementam a matriz curricular.

Os esforços de entender a matriz curricular do curso de Arquitetura e Urbanismo da UNOCHAPECÓ e incorporar o BIM no currículo, integradas a interdisciplinaridade e as competências em BIM que se requer ao aluno, tem por objetivo uma implementação futura.

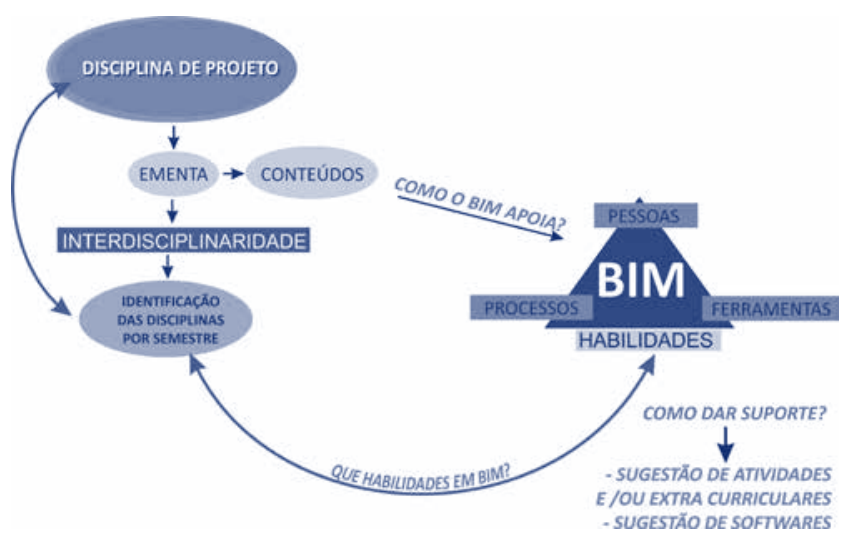

Figura 07: Esquema da estruturação da proposta. 


\section{Considerações finais}

O corpo docente do curso de Arquitetura e Urbanismo da UNOCHAPECÓ se dividem: 1) nos que realmente querem implementar o BIM é já tem contato com as ferramentas, 2) os que estáo motivados a conhecer e aprender e 3) os que talvez acreditam que não é necessário conhecer as ferramentas para se inserir neste processo. Mas em todos os casos observou-se uma disposição para mudança, por entenderem o BIM como potencial.

Quanto ao conhecimento das ferramentas, pensa-se que alguns professores devem sim dominá-las associadas as suas linhas dentro da matriz. Mas considera-se mais importante estimular o aluno para a mudança no processo que envolve náo apenas o uso das ferramentas, mas incorporar as práticas colaborativas, interdisciplinares e integradas. Neste sentido, o papel do professor está em orientar o uso correto da ferramenta e explorá-la como potencial para o processo de ensino-aprendizagem, e náo propriamente no ensino dos recursos, da mesma.

Entende-se que a ferramenta por si só não mudará o processo se não houver uma mudança de atitude. Como também sem a tecnologia não se consegue chegar ao resultado pautado em todo o conceito BIM.

Optar por uma matriz, que insere novas tecnologias e processos, a exemplo do BIM, é assumir uma nova forma de ensinar e exige maior integração, colaboração e interdisciplinaridade. Os resultados, quanto a implementação do BIM no ensino no curso de arquitetura e urbanismo, da UNOCHAPECÓ, dependem da sua aplicação, mas acredita-se que o primeiro passo foi dado, visualizando o BIM como potencial para o processo de ensino-aprendizagem.

O mercado da construçáo civil precisa avançar e necessita de profissionais com um novo perfil, que saibam trabalhar de forma integrada, interdisciplinar e colaborativa, abertos a novos processos e tecnologias. Entende-se que a resposta se dá através da educação, buscando inovar, experimentar, aprender com os erros. O caminho não é fácil, mas pode se tornar menos árduo com a colaboração de todos.

\section{Referências}

Barison, m. B.; santos, e. T. Ensino de BIM: tendências atuais no cenário Internacional. Gestão \& Tecnologia de Projetos,
São Carlos, v. 6, n. 2, p. 67-80, dez. 2011. Disponível em: <http://www.iau.usp.br/posgrad/gestaodeprojetos/index.php/ gestaodeprojetos/article/view/218>. Acesso em 11 jan. 2013

Delatorre, Vivian. Potencialidades e limites do BIM no ensino de Arquitetura: Uma proposta de implementaçáo; orientadora, Alice Theresinha Cybes Pereira. Dissertação. Universidade Federal de Santa Catarina, Florianópolis, SC, 2014. 293p.

Eastman, Chuck; TEICHOLZ, Paul; Sacks, Rafael; Liston, Kathleen. BIM Handbook: A Guide to Building Information Modeling for Owners, Managers, Designers, Engineers and Contractors. Hoboken (NJ): John Wiley \& Sons, 2008.

Lakatos, Eva Maria. Fundamentos da Metodologia Científica / Marina de Andrade Marconi, Eva Maria Lakatos. - 6. ed. - 6. reimpr. - São Paulo: Atlas, 2008. 315p.

Kiviniemi, Arto. Challenges and opportunities in the BIM education How to include BIM in the future curricula of AEC professionals?. 2013. Disponível em: <http://www.nibs.org/?page=conference_bim $>$. Acesso em: 20 out. 2013.

Ruschel, R. C. et al. O ensino de BIM: Exemplos de implantação em cursos de Engenharia e Arquitetura. In: ENCONTRO NACIONAL DE TECNOLOGIA DE INFORMAÇÃO E COMUNICAÇÃO NA CONSTRUÇÃO CIVIL, 5., Salvador, 2011. Anais ... Salvador: LCAD/PPGAU-UFBA, 2011.

Ruschel; Andrade; Morais.. O ensino de BIM no Brasil: Onde estamos?. Ambiente Construído. Ambient. constr. vol.13 no.2 Porto Alegre Apr./Jun 2013. Disponível em: < http:// dx.doi.org/10.1590/S1678-86212013000200012>. Acesso em: jul. 2013.

Succar, B. Building Information Modeling framework: a research and delivery foundation for industry stakeholders. Automation in Construction, v. 18, n. 3, p. 357-375, 2008. Disponível em:<www.elsevier.com/locate/autcon>. Acesso em: 20 jan. 2013.

Taylor, J.M.,LIU,J.; Hein ,M.F.(2008). Integration of Building Information Modeling into an ACCE Accredit construction management curriculum. 44th ASC Annual International Conference, Associated Schools of Construction, Auburn, AL. 2008 Disponível em: <http://ascpro0.ascweb.org/archives/ cd/2008/paper/CEUE246002008.pdf>. Acesso em 10 jan. 2013 